\title{
A DIMENSÃO ESPACIAL DA ESCOLA PÚBLICA: LEITURAS SOBRE A REORGANIZAÇÃO DA REDE ESTADUAL DE SÃO PAULO*
}

\author{
Eduardo Donizeti Girotto ${ }^{1}$
}

\begin{abstract}
RESUMO: $\mathrm{O}$ artigo discute o projeto de reorganizaçáo escolar apresentado pela Secretaria Estadual de Educaçáo de São Paulo no segundo semestre de 2015, buscando compreender as implicaçóes socioespaciais do mesmo. Para tanto, articulou-se o debate teórico desenvolvido por diferentes autores nas últimas décadas sobre a dimensão espacial da educação e da escola pública no Brasil, com as análises construídas a partir dos dados do atual projeto de reorganização escolar. Trata-se de pesquisa em andamento e, por isso, o que se apresenta aqui são as primeiras análises dos mapeamentos e trabalhos de campo realizados no contexto da apresentação da proposta de reorganização escolar e das ocupaçóes de escolas. Em decorrência do tamanho da rede estadual de educação, optou-se por desenvolver a análise a partir das informaçóes das escolas estaduais localizadas na cidade de São Paulo. Em nossa perspectiva, o fechamento de escolas proposto no projeto de reorganização pode acentuar a desigualdade espacial da escola pública em São Paulo. Por isso, a importância da luta dos estudantes secundaristas que reafirma, entre outras coisas, a relação entre a escola, seus sujeitos e espacialidades.
\end{abstract}

Palavras-chave: Reorganização escolar. Dimensão espacial. Escola pública. Desigualdade socioespacial.

\section{THE SPACE DIMENSION OF THE PUBLIC SCHOOL: READINGS ON THE REORganization of THE Network STATE of SÃo PaUlo}

ABSTRACT: This paper discusses the school reorganization project presented by São Paulo Secretary of Education, in 2015, seeking to understand its space implications. For this purpose, we relate the theoretical discussion developed by many researchers in the last decades about public education and school in Brazil, with analyses build from data about the current school reorganization project. This is ongoing

\footnotetext{
*Resultado parcial de pesquisa do Projeto "A Reorganização Escolar em Mapas", realizado no Laboratório de Ensino e Material Didático do Departamento de Geografia da Universidade de São Paulo.

${ }^{1}$ Universidade de São Paulo, Departamento de Geografia - São Paulo (SP), Brasil.

E-mail: eduardo.girotto128@gmail.com

DOI: 10.1590/ES0101-73302016167626
} 
research and, therefore, the first analyzes of mapping and field work in the context of the presentation of the school reorganization proposal and school occupations are presented here. Due to the size of the school state network, we chose to develop our analyses from the data of states schools located at the city of Sáo Paulo. In our view, the closure of schools proposed in the reorganization project can enhance the spatial inequality of public school in São Paulo. Therefore, the importance of the struggle of high school students reaffirm, among other things, the relationship between the school, its subject and spatiality.

Keywords: School reorganization. Spatial dimension. Public school. Socio-spatial inequality.

\section{LA DIMENSION SPATIALE DE L'ÉCOLE PUBLIQUE: DES LECTURES SUR LA RÉORGANISATION DU RÉSEAU SCOlaire de l'état de São Paulo}

RÉSUMÉ: Dans cet article, nous discutons le projet de réorganisation scolaire présenté par le Département de l'éducation de l'état São Paulo dans la seconde moitié de 2015, en cherchant à comprendre ses implications socio-spatiales. Pour cela, nous avons articulé le débat théorique sur la dimension spatiale de l'éducation et de l'école publique au Brésil, mis au point par de différents auteurs au cours des dernières décennies, avec l'analyse construite à partir de la conception actuelle des données de réorganisation de l'école. Cette recherche est encore en cours et, par conséquent, ce que nous présentons ici, sont les premières analyses de cartographie et de travail sur le terrain dans le cadre de la présentation de la proposition de réorganisation et occupation de l'école. En raison de la taille du reseau scolaire de l'état, nous avons choisi de développer l'analyse des informations provenant des écoles publiques situées dans la ville de São Paulo. À notre avis, la fermeture des écoles proposée dans le projet de réorganisation peut faire ressortir l'inégalité spatiale de l'école publique à São Paulo. Ainsi, il est important la lutte des lycéens qui réaffirme, entre d'autres choses, la relation entre l'école, ses sujets et les spatialités.

Mots-clés: La réorganisation de l'école. Dimension spatiale. École publique. Inégalités socio-spatiales.

\section{Introdução}

ecentemente, o governo do estado de São Paulo apresentou um polêmico projeto de reorganização escolar. Defendido como necessário para a ampliação da qualidade do processo educativo, o projeto pressupunha 
a divisão das escolas em ciclos de aprendizagem: uma escola para os alunos do $1^{\circ}$ ao $5^{\circ}$ ano; outra para os alunos do $6^{\circ}$ ao $9^{\circ}$ ano; e uma terceira para os alunos do ensino médio. Apresentada de forma rápida e arbitrária, tal reorganização não possibilitou aos diferentes sujeitos da rede estadual de educação de São Paulo discutir o projeto ou participar de sua elaboraçáo, negando, assim, o espaço do contraditório, essencial no processo democrático. Com isso, em outubro de 2015, o governo paulista anunciou o fechamento de 94 escolas em todo o estado, sendo 25 delas na cidade de São Paulo.

Como resposta à ação não dialógica do governo estadual, alunos e alunas de mais de duas centenas de escolas públicas em todo o estado de São Paulo iniciaram um intenso processo de ocupação de escolas, em um amplo movimento de enfrentamento ao projeto de reorganização. No movimento, princípios como autogestão, ação direta, apoio mútuo e solidariedade foram afirmados, não como discursos, mas como açóes cotidianas daqueles que, cansados de serem tratados como números, afirmaram-se como sujeitos do seu próprio processo formativo. Após um mês de ocupaçóes, o governo estadual viu-se obrigado a recuar, decretando a suspensão do projeto e prometendo construir o diálogo com a sociedade civil.

Tanto na proposta apresentada pelo governo quanto na reação organizada pelos estudantes secundaristas, emerge uma dimensão fundamental da escola pública: o seu enraizamento territorial. Ocultando essa dimensão a partir de uma série de dados e informaçóes que buscavam apresentar as escolas e os seus sujeitos como abstratos, desconectados do seu entorno e da comunidade que lhe dá vida e sentido, o governo estadual apresentou a proposta que implicaria, se posta em prática, em uma profunda mudança na relação socioespacial dos alunos e alunas entre si e com as suas escolas. Como resposta, a luta dos estudantes secundaristas trouxe à tona a dimensão territorial das escolas públicas, reafirmando-as como espaços de construção de identidades, de diálogos e de conflitos. Propor a realocação (esse foi o termo utilizado pelo governo estadual) de mais de 700 mil alunos, como previsto no projeto de reorganização, é produzir outra ordem socioespacial da escola pública no estado de São Paulo, que atende a interesses muito além do discurso da busca por certa "qualidade educacional", os quais, estrategicamente, foram ocultados.

Diante disso, este artigo discute a proposta de reorganização escolar da rede estadual de São Paulo, buscando apresentar algumas problematizaçóes com o intuito de ressaltar a dimensão espacial do projeto, os interesses presentes nele, seus sujeitos e estratégias. Trata-se de pesquisa inicial e, portanto, limitada às primeiras impressóes e hipóteses construídas no processo de investigação junto ao Laboratório de Ensino de Geografia e Material Didático da Universidade de São Paulo (USP). Trata-se de pesquisa em andamento e, por isso, o que apresentamos aqui são as primeiras análises dos mapeamentos e trabalhos de campo 
realizados no contexto da apresentação da proposta de reorganização escolar e das ocupaçóes de escolas. Além disso, as dificuldades para obtenção de dados oficiais têm se constituído como uma das barreiras para um avanço mais rápido da nossa investigação. De qualquer forma, pensamos ser produtivo partilhar tais impressóes e hipóteses com a comunidade científica, a fim de, inclusive, ampliar o debate sobre uma temática tão fundamental para a educação pública no estado de São Paulo.

Organizamos, dessa forma, o presente artigo em três momentos. No primeiro, retomamos as pesquisas de Pereira, Spósito, Algebaile, Haroldo Gama Torres et al., Gilberto Cunha França, entre outros pesquisadores que têm discutido os sentidos que a escola pública tem no Brasil, com o intuito de entender o seu movimento contraditório de constituição e sua distribuição espaço-temporal profundamente desigual. No segundo, analisaremos a atual proposta de reorganização da rede estadual de educação de São Paulo, articulando-a com as demandas do ajuste neoliberal que vem norteando as políticas do Estado brasileiro desde, pelo menos, a década de 1990 (com poucos momentos de efetiva ruptura, que reforçam uma política espacial). Por fim, discutiremos como a luta dos secundaristas contra o projeto de reorganização escolar significou um movimento de reafirmação da dimensão espacial da escola pública, defendendo-a como lugar de luta, diálogo e de produção coletiva de identidades.

\section{A dimensão espacial da escola pública: revisitando uma problemática}

A relação entre a escola pública e o seu entorno tem um importante campo de investigação nas pesquisas sobre educação. Um dos primeiros trabalhos sobre o tema, intitulado $A$ escola numa área metropolitana, foi realizado por Pereira, em 1967, e orientado por Florestan Fernandes, na Faculdade de Filosofia, Ciências e Letras (atual Faculdade de Filosofia, Letras e Ciências Humanas) da USP. O trabalho investigou as diferentes implicaçôes resultantes da relação entre escola e comunidade, ressaltando a importância do entendimento da dimensão espacial da escola pública para a compreensão daquilo que ocorre no interior da mesma. $\mathrm{Na}$ análise, o autor buscou fugir de uma leitura marcada por certo determinismo ambiental, no qual as condiçóes socioespaciais do entorno da escola seriam suficientemente viáveis para explicar aquilo que ali ocorre. $\mathrm{Na}$ discussão, afirma-se o pressuposto de que a dinâmica socioespacial da comunidade escolar deve ser levada em consideração nas diferentes açóes planejadas e desenvolvidas pelos sujeitos escolares, entendendo, assim, a relação intrínseca entre a escola e a comunidade do entorno.

Outras duas importantes obras que abordam a temática são os trabalhos de Spósito, O povo vai à escola (1984) e A ilusão fecunda (1993). Ambos analisam 
a luta pela construção de uma escola pública para todos, tanto no acesso quanto na permanência e na qualidade do ensino, na cidade de São Paulo, a partir da década de 1940. Em A ilusão fecunda, Spósito faz um estudo detalhado das condiçóes e dos processos que resultaram no surgimento de importante movimento popular na zona leste da cidade de Sáo Paulo. Tal movimento iniciou um intenso processo de luta pelo direito à educação que acabou por se expandir na direção de novas reivindicações e mobilizaçóes. Para além de uma leitura que busca entender a luta pela educação como um fim em si mesmo, a autora busca compreender de que forma tal movimento articulou as diferentes reivindicaçóes com a problemática urbana ali presente. Para a autora,

As dificuldades de acesso à terra, transformando São Paulo em uma cidade clandestina do ponto de vista da situação legal, trouxeram novas demandas por equipamentos escolares em bairros ainda inexistentes para o poder público, demandas cada vez mais limitadas pelos problemas do uso privado do solo (SPÓSITO, 1993, p. 53).

A partir das análises desenvolvidas nessa obra, abre-se um importante caminho de pesquisa no âmbito das políticas educacionais e dos movimentos reivindicatórios, que aponta a necessidade de se entender as diferentes dimensóes presentes nesse processo. No caso específico do trabalho de Spósito, a luta pela abertura de escolas pública foi compreendida também como uma das formas de resistência ao intenso processo de espoliação urbana (KOWARICK, 1979) que atinge os moradores das periferias da cidade de São Paulo. Em situação de quase clandestinidade, enquanto objetos e sujeitos do processo de urbanização, os moradores da periferia paulistana iniciaram um movimento que, em certa medida, buscou discutir o sentido da cidade, expandindo a luta pelos direitos básicos de cidadania, como educação, saúde, moradia, cultura, lazer, entre outros. Dessa forma, ao lutarem pelo direito à educação, tais moradores buscaram inverter a lógica da espoliação urbana que os levou a habitar os limites da cidade. $\mathrm{O}$ movimento pela educação, articulado com os outros movimentos sociais, é, portanto, mesmo que parcial, uma luta pelo direito à cidade (LEFEBVRE,1969) - pelo direito ao urbano que só se pode realizar a partir da superação das contradiçóes que marcam a reprodução social.

A escola pública na periferia paulistana se configura, portanto, nas análises construídas na obra de Spósito (1993), também enquanto resultado da luta pela reapropriação dos espaços da cidade e da vida. Mesmo que de forma breve, trata-se da conquista e realização de um direito de discutir a organização da cidade, dos seus lugares e usos, dentre os quais se destaca a escola pública. Tais movimentos de luta, pelo menos em gérmen, constituem-se enquanto espaços plurais de formação política, que, na práxis, produzem a consciência da cidadania a partir do entendimento de como a mesma é negada cotidianamente pela exclusão dos 
direitos que se materializam espaço-temporalmente na cidade. Nesse processo de luta, a crítica à urbanização nos moldes como ela se apresenta, gerida pelos interesses dos grandes grupos econômicos, está posta. Aos poucos, os participantes desses movimentos passam a reivindicar não apenas o direito à educação, mas toda infraestrutura e condiçóes necessárias para que a cidadania plena possa ser realizada. Tal luta, portanto, transforma-se em uma luta pelo direito à cidade.

As exigências dos equipamentos de uso coletivo, ao propiciarem o aparecimento das lutas sociais, transformam seus protagonistas - trabalhadores, mulheres, jovens e crianças. Há um acúmulo de experiências, redes de sociabilidades se desenvolvem e nessa trajetória já não mais se torna possível a compreensáo em profundidade de um dos aspectos da luta social - as demandas educativas - se ele não estiver articulado às demais formas de enfrentamento desenvolvidas pelas classes populares moradoras da periferia urbana da cidade de São Paulo (SPÓSITO, 1993, p. 53).

Vale ressaltar que tais lutas, principalmente na zona leste de São Paulo, resultaram em profundas transformaçóes socioespaciais, articuladas com a ampliação da educação pública. É possível traçar paralelos entre os movimentos de luta pela construção do campus da USP e da criação da Universidade Federal de Sáo Paulo (Unifesp), campus da Zona Leste, com os movimentos descritos por Spósito em seu trabalho. A experiência política que resultou da luta pela educação pública tem contribuído para a continuidade de mobilização dos moradores daquela região, demonstrando como, a partir de uma pauta específica, os movimentos se reinventam e se articulam. As análises desenvolvidas por Spósito nos possibilitam compreender como tal entendimento da dimensão espacial da escola pública contribui para o pensamento sobre o direito à educação e sua relação com a luta pelo direito à cidade.

Mais recentemente, Algebaile (2009) demonstrou, em sua tese de doutorado, a importância do entendimento da dinâmica espacial da educação. A autora analisou como o espraiamento territorial da escola pública (um dos poucos serviços públicos que chegam a determinados pontos do território nacional) vem sendo utilizado pelos diferentes entes federativos para a difusão de políticas de cunho assistencialista. Como aponta a autora,

De fato, a gradativa distribuição da escola no território nacional náo ocorreria desvinculada de contextos de organizaçáo institucional nos quais a possibilidade de presença da escola ensejava definiçóes acerca da ausência ou das formas de presença de outras instituiçóes, serviços e açóes. A presença da escola em lugares marcados por ausências conferiu a essa instituição um sentido estratégico excepcionalmente amplo (ALGEBAILE, 2009, p. 328). 
Nessa dinâmica da ausência-presença do Estado em determinados lugares do território nacional, a escola pública tem se tornado local estratégico para a difusão de certas políticas. Por conta de seu espraiamento territorial, ela passa por um processo de hiper-responsabilização, tendo que dar conta de diferentes açóes que fogem à alçada de sua competência e que reforçam a sua dimensão espacial. Em sua tese, a autora investiga a relação entre a expansão da rede pública no Brasil e aquilo que denominou de "gestão da pobreza", ressaltando, principalmente, o uso instrumental da escola na realização de determinadas políticas com esse intuito. $\mathrm{Na}$ análise feita pela autora, tal processo é investigado levando em consideraçáo o programa Bolsa Escola - elaborado durante o segundo mandato presidencial de Fernando Henrique Cardoso e um dos pilares do Programa Bolsa Família, uma das marcas do governo do ex-presidente Luiz Inácio Lula da Silva. Para a autora,

A escola tem uma presença territorial e permite uma penetração que o restante do Estado não tem; nesse sentido, sua escolha como um posto de realizaçáo do Bolsa Escola fazia parecer que o programa, chegando a todos os lugares, chegava a todos os pobres, simulando-se uma universalidade que o programa não tinha. É nesse sentido que a escola pública fundamental se consolidaria como Estado dos pobres no Brasil (ALGEBAILE, 2009, p. 234).

Essa relação entre escola e pobreza urbana também está no centro dos textos apresentados no livro $A$ cidade contra a Escola? - segregaçáo urbana e desigualdades educacionais em grandes cidades da América Latina, organizado por Ribeiro e Kaztman (2008). Em um dos artigos, que analisa os resultados da dinâmica escolar levando em consideração unidades localizadas em áreas centrais e periféricas da cidade de Sáo Paulo, Torres et al. (2008) buscam desconstruir uma concepção que tem norteado, pelo menos no discurso, uma série de políticas educacionais, as quais reduzem a compreensão daquilo que acontece na escola aos fatores internos da mesma. No entanto, o que a pesquisa demonstra é a importância de se compreender a forma com que a dinâmica da unidade escolar está relacionada com os processos que ocorrem no seu entorno e que são profundamente espacializados. Essa espacialização da pobreza (e, portanto, das condiçóes materiais de alunos e alunas para a experiência educacional) não pode ser posta de lado como fazem as políticas de ranqueamento baseadas nos textos padronizados. Tal condição não é secundária, mas afeta sobremaneira a forma como alunos e professores constroem a prática educativa em sua vivência cotidiana. Como apontam os autores,

Ao conseguir incluir alunos muito pobres, a escola pública tal como existia até então não parece saber muito bem o que fazer com eles. Nesses casos, aplicar as mesmas regras universais re- 
lacionadas à distribuição de recursos, alocação de profissionais e critérios de transferência implica manter intacto o quadro de desigualdades educacionais entre escolas de centro e periferia (TORRES et al., 2008, p. 85).

É preciso, portanto, espacializar as políticas educacionais, reconhecendo a desigualdade socioespacial da escola pública no estado de São Paulo, correndose o risco de, não agindo assim, ampliá-la. Para tanto, a dimensão espacial da desigualdade é uma das variáveis que precisam ser levadas em consideração na construção de políticas públicas em diferentes áreas. Esta é uma perspectiva de pesquisa no campo da geografia e educação que temos construído desde 2006, analisando as implicações político-pedagógicas da dimensão espacial da escola pública na regiáo metropolitana de São Paulo e que resultou em dissertaçấo de mestrado (GIROTTO, 2009). Trata-se de reconhecer a condição espacial como variável indispensável na construção, implementação e análise de políticas educacionais em diferentes escalas

Referindo-se à realidade francesa, Ben Ayed (2012) aponta a existência de uma tentativa de ocultação da dimensão espacial das desigualdades educacionais no país. Tal tentativa se dá, segundo o autor, por meio de políticas educacionais de caráter burocrático e tecnicista que instigam o desenvolvimento de açóes que pouco dialogam com as desigualdades territoriais da escola pública francesa. A partir dessa constatação, o autor iniciou um processo de investigação com o intuito de construir indicadores sobre a educação francesa que fossem capazes de verificar a importância da dimensão espacial da educação em diferentes processos, como, por exemplo, a aprendizagem discente. Para o autor, a partir do amplo espectro de dados e pesquisas produzidos, "é impossível ocultar a problemática local e os efeitos territoriais para pensar a questão das desigualdades de escolarização" (BEN AYED, 2012, p. 800).

Portanto, os diferentes autores abordados nesta revisão da literatura científica têm demonstrado a importância tanto da produção de políticas que levem em consideraçáo a dimensáo espacial da escola pública quanto da compreensão dessa dimensão no Brasil e no mundo. No entanto, não é essa a concepção norteadora do projeto de reorganização da rede estadual de Educaçáo em São Paulo, como discutiremos a seguir.

\section{A reorganização escolar: da escola abstrata à escola de luta}

O projeto de reorganização da rede estadual de educação de São Paulo foi apresentado pelos seus idealizadores como decorrente de um processo natural de modificaçáo do perfil demográfico e educacional do estado. Segundo a Secretaria Estadual de Educação, tal processo resultou no aparecimento de 
"classes e escolas ociosas", que precisariam ser reorganizadas com o intuito de se constituírem escolas com ciclos únicos de aprendizagem. Tal necessidade se justificaria, segundo dados da Secretaria, por pesquisas (cujas fontes não são informadas) que comprovariam que nesses ciclos os alunos aprendem mais. Em uma série de vídeos postados no site da Secretaria, especialistas ligados ao governo defendem a proposta, reafirmando que a única preocupação com essa reformulação é garantir melhor qualidade para a educação de crianças, adolescentes e jovens do estado.

Nesse debate, é fundamental ampliar a discussão, uma vez que no campo das pesquisas sobre ensino-aprendizagem na educação escolar há uma consolidação de resultados que demonstram que são diversas as variáveis que influem no processo. Por exemplo, ao revisitar a literatura científica nesse campo de investigação, é possível afirmar que os alunos e alunas aprendem mais em salas com turmas menores, quando têm acesso a laboratórios de ciência, informática, quando podem realizar trabalhos de campo, estudos do meio, quando têm possibilidade de visitar museus, teatros, cinemas. Os alunos e alunas aprendem mais quando o professor não precisa ter 30 turmas para completar sua carga horária, quando não se vê obrigado a dar atendimento individual para 900 alunos por semana, quando não tem que se desdobrar em três escolas, de três redes diferentes, para conseguir pagar as contas ao final do mês. Os alunos aprendem mais quando o professor tem tempo para preparar as aulas, quando sua formação continuada está vinculada aos problemas reais do cotidiano escolar, quando não é obrigado a preparar os alunos para a realizaçấo de testes padronizados, quando é valorizado, material e imaterialmente. Enfim, analisar, a partir de uma única variável, uma problemática que, por excelência, é multifacetada constitui um equívoco substancial que pode contribuir para agravar a situação em vez de construir possibilidades de enfrentamento. Por isso, em nossa perspectiva, para além do discurso da qualidade da educaçáo aventado pelo governo estadual como um dos motes para a realização do projeto de reorganização escolar, há muito mais elementos a serem considerados.

Entre as hipóteses investigativas que podem ser trilhadas nesta inquirição dos interesses e implicaçóes vinculados ao projeto de reorganização escolar está a compreensão da dimensão espacial do mesmo. Em pesquisa recente, França (2010) constrói uma análise que articula o processo de fechamento de unidades escolares da rede estadual na cidade de Sáo Paulo com o avanço de processos de produção e valorização do espaço urbano. $\mathrm{O}$ autor analisa o fechamento de escolas da rede estadual no período entre 1995 e 2005, na Diretoria de Ensino Centro-Oeste, na cidade de São Paulo ${ }^{1}$. No período, foram extintas 13 unidades escolares que tinham como características comuns serem escolas antigas, formadas nas primeiras décadas do século XX e que atendiam alunos e alunas vindas de bairros da periferia da regiáo oeste da cidade. Na pesquisa, França analisa os usos feitos dos prédios escolares após o fechamento das unidades. Segundo o autor, 
As escolas extintas foram ao mesmo tempo reutilizadas para novas funçóes. Apenas partes de 3 foram reutilizadas para atividades diretamente escolares. As demais foram reutilizadas em atividades administrativas da SEE e em atividades de outras Secretarias do Estado, inclusive de Segurança Pública. Assim, os próprios prédios escolares esvaziados pelas transformaçóes urbanas e demográficas são, no ajuste produtivo, reutilizados para funções de serviços, reforçando as características funcionais das áreas centrais da metrópole de São Paulo, na sua função de gestão da periferia e do território nacional (FRANÇA, 2010, p. 110).

Houve também a incorporação dos terrenos das escolas na lógica de produção do espaço urbano na cidade de São Paulo, como mostra a reportagem publicada pelo jornal Diário de Sáo Paulo, no dia 7 de novembro de 2015 (Figura 1). Há que se ressaltar que, segundo Adrião (2008), entre 1995 e 1998, foram fechadas 864 escolas em todo o estado de Sáo Paulo, em um universo de 5919 unidades escolares.

Ao analisar o caso de tentativa de fechamento de outras duas escolas públicas na regiáo da Diretoria de Ensino Centro-Oeste (EE Alves Cruz e EE Martin Francisco), o autor demonstra os múltiplos interesses ali presentes, compreendendo o processo de incorporaçáo dos terrenos das unidades escolares no processo de valorização do espaço urbano na cidade de São Paulo. A pesquisa de França (2010) demonstrou a importância de entendermos a dimensão espacial do processo de reorganizaçáo escolar que vem sendo posta em prática na rede estadual de São Paulo desde 1995. Tal dimensão precisa ser entendida na dinâmica de produçáo e reproduçáo do espaço urbano, diretamente vinculado aos interesses dos agentes do mercado imobiliário.

Em 2015, no momento da divulgação da lista das escolas que iriam ser fechadas no município de São Paulo (Figura 2), produzimos uma investigaçâo com os alunos e alunas do Departamento de Geografia da USP, na disciplina de Estágio Supervisionado de Ensino de Geografia e Material, com o intuito de construir primeiras aproximações com a dimensão espacial da problemática.

Em uma primeira análise dessa distribuição espacial, é possível verificar que há uma concentração de escolas estaduais a serem fechadas na zona oeste da cidade de São Paulo (11 unidades). Tal concentração nos levou a ampliar a investigação construída por França (2010), uma vez que, como o autor demonstrou, já havia um precedente de fechamento de unidades escolares nessa área da cidade de São Paulo. A ideia, seguindo as análises construídas pelo autor em sua tese, era verificar se a lógica de articulação entre o fechamento de escolas e o processo de valorização do espaço urbano continuava a ter validade explicativa. A Figura 3 oferece um mapa dos resultados da investigação preliminar. 
A E.E. Mary Moraes constava na lista das escolas estaduais que iriam ser fechadas em 2016 e ganhou os noticiários quando foi cercada por carros da polícia por conta da ocupação realizada pelos estudantes e seus pais (Figura 4). Essa visibilidade ocorreu pelo absurdo do acontecimento: por se tratar de uma escola que atende estudantes dos anos iniciais do ensino fundamental, os carros de polícia acabaram por cercar uma escola repleta de crianças de 6 a 10 anos que pediam o náo fechamento da unidade escolar. A quantidade de lançamentos imobiliários, residenciais e comerciais, no entorno da escola nos permite inferir uma possível relação do fechamento dessa unidade com o processo de produção do espaço (Figura 5). Isso se torna ainda mais evidente quando, em trabalho de campo realizado, descobrimos que essa unidade escolar já atuava com ciclo único, o que gerou mais dúvidas em relação às reais intençōes presentes no projeto de reorganização escolar (Figura 6).

Fenômeno semelhante foi encontrado na análise do entorno da E.E. Paulo Machado de Carvalho, situada no bairro Bela Vista, regiáo central da cidade de São Paulo. A visita ao entorno da escola nos possibilitou entender a dinâmica imobiliária: a escola encontra-se cercada por lançamentos imobiliários (conforme mostram as Figuras 7 e 8) destinados à classe média alta em um processo de revalorização urbana dessa região.

Da mesma forma que a Mary Moraes, a E.E. Paulo Machado de Carvalho também era de ciclo único (atendia apenas aos anos iniciais do en-

\section{Figura 1}

Reportagem sobre a construção de prédios em terrenos de escolas fechadas.

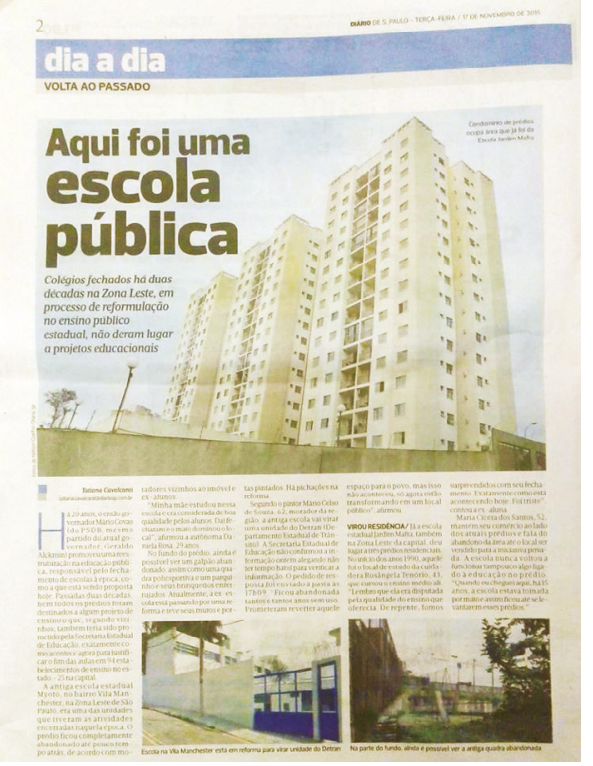

Fonte: Jornal Diário de São Paulo, 7 de novembro de 2016. 


\section{Figura 2}

Localização das 25 escolas que estavam na lista de fechamento na cidade de Sáo Paulo, segundo o projeto de reorganizaçáo.

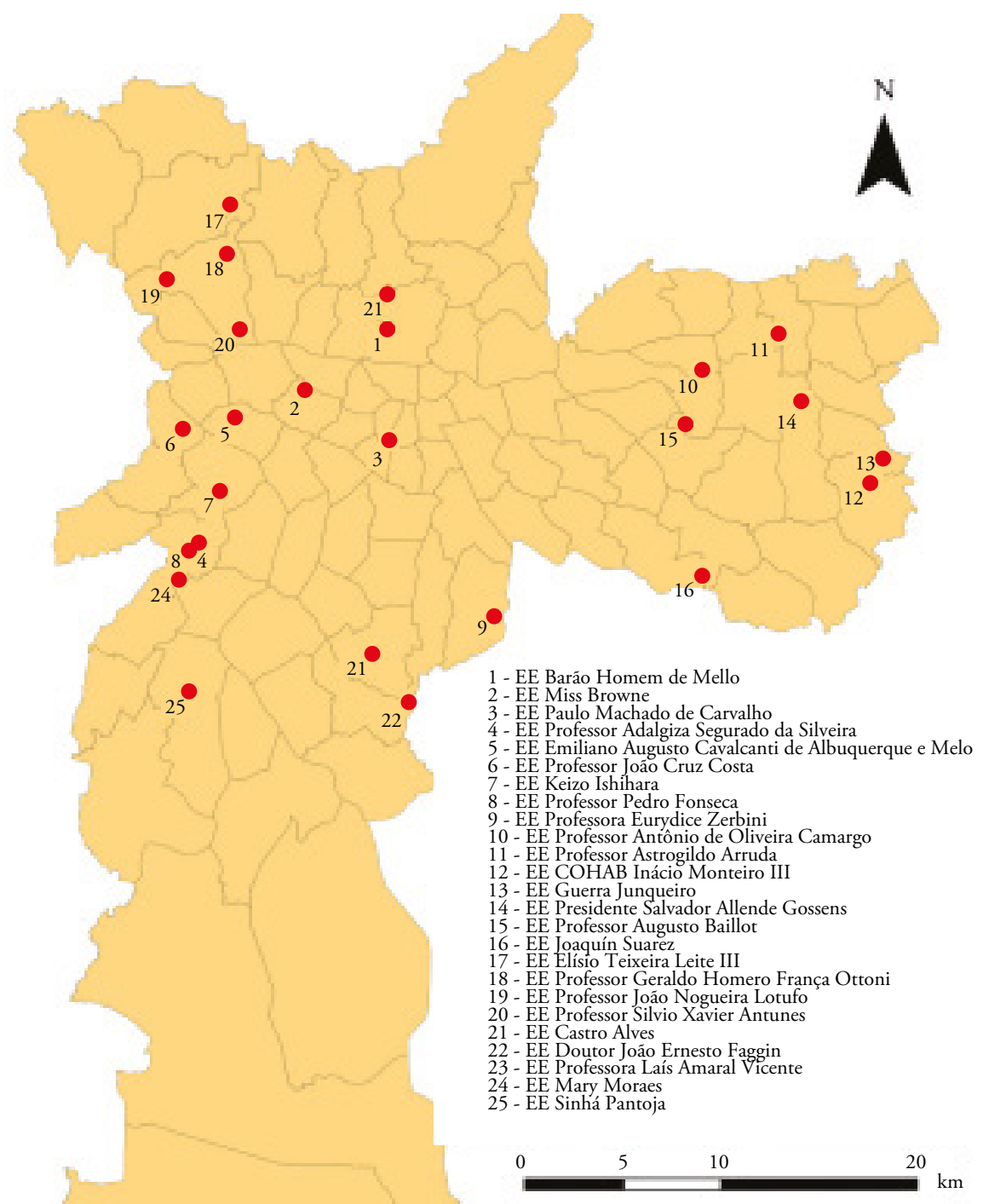

Base cartográfica: Mapa Digital da Cidade SAD 69 - Projeção UTM.

Fonte dos dados: Secretaria da Educaçáo do Estado de Sáo Paulo. Elaborado no ArcGis 9.3.

Fonte: elaborado por alunos e professor da disciplina de Estágio Supervisionado de Ensino de Geografia (2. ${ }^{\circ}$ semestre de 2015). 


\section{Figura 3}

Lançamentos imobiliários no entorno da E.E. Mary Moraes na cidade de São Paulo.

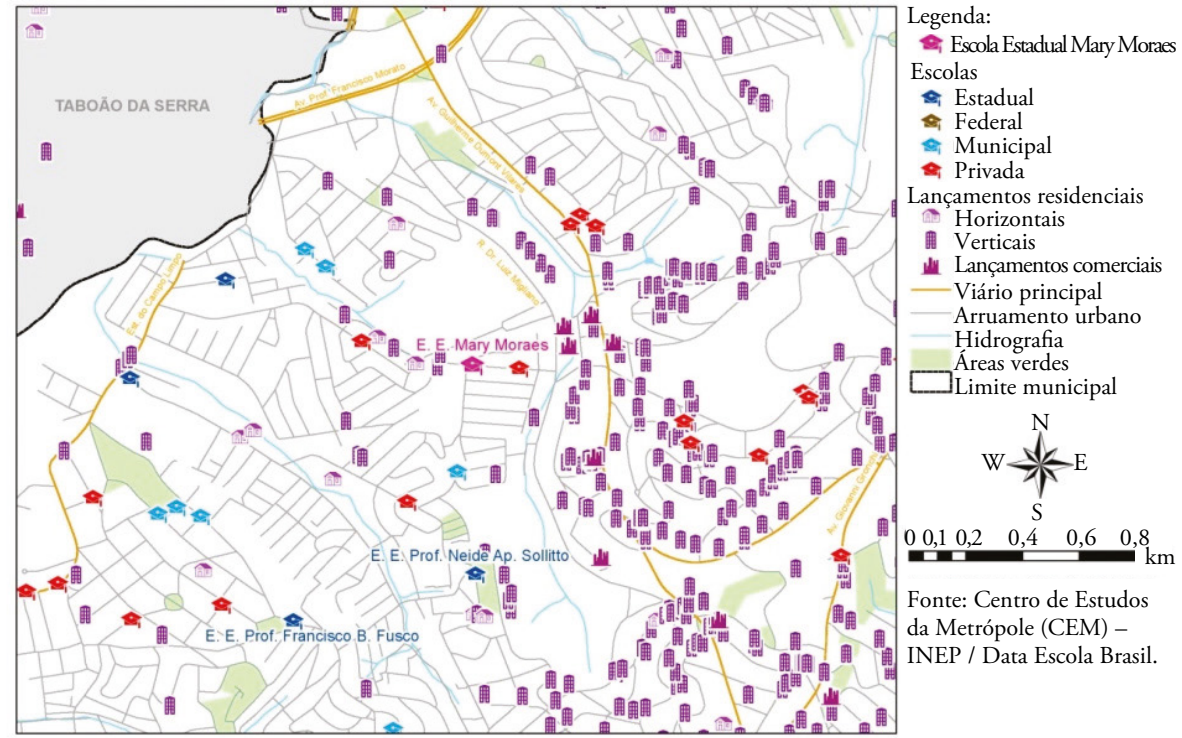

Fonte: elaborado por alunos e professor da disciplina

de Estágio Supervisionado de Ensino de Geografia (2o semestre de 2015).

\section{Figura 4}

Entorno do E.E. Mary Moraes.

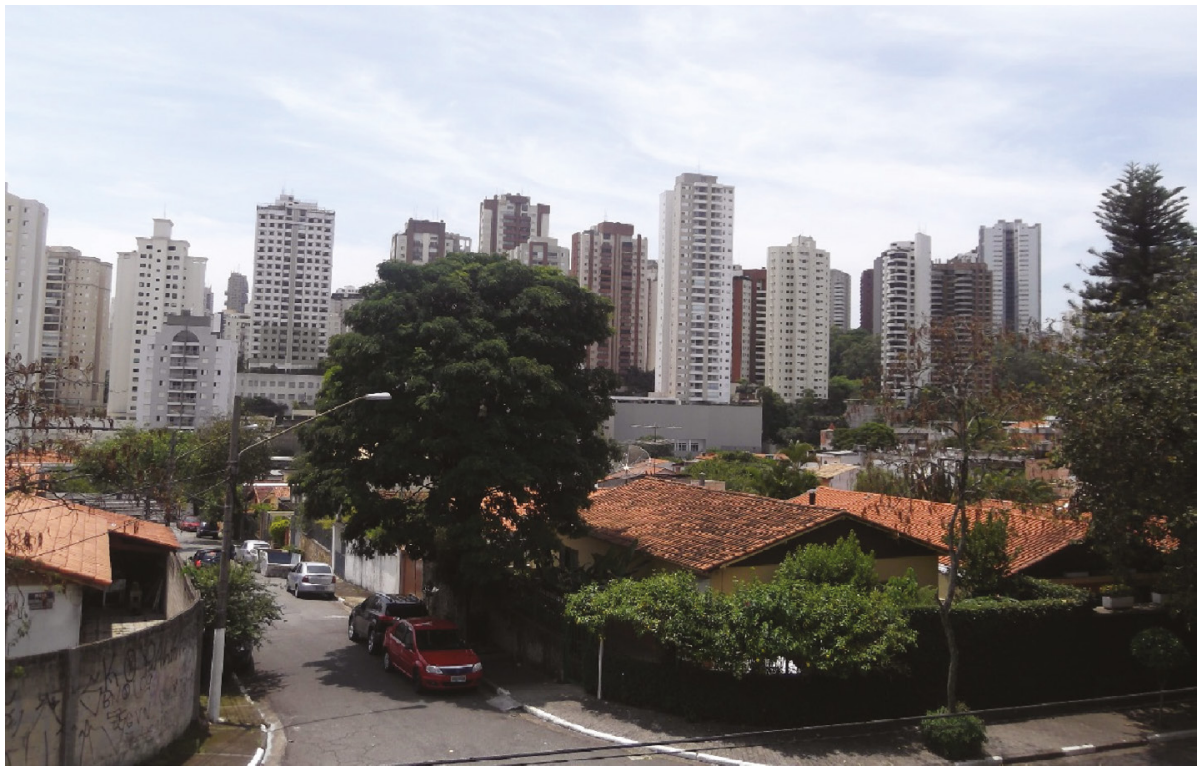

Fonte: trabalho de campo da disciplina de Estágio

Supervisionado em Ensino de Geografia, CHASSOT, T., novembro de 2015. 
sino fundamental). Tal incongruência reforça a necessidade de se construir pesquisas com vistas a entender as diferentes dimensóes que estáo no cerne do processo de reorganizaçáo escolar da rede estadual de São Paulo, mas que se encontram ocultas no discurso dos responsáveis pela elaboração e implementação da proposta.

No caso da E. E. Paulo Machado de Carvalho, nossa hipótese investigativa busca correlacionar o amplo processo de gentrificaçăo ${ }^{2}$ que tem ocorrido em determinados territórios da área central de São Paulo, resultando na expulsão de uma parcela importante da população mais pobre. Tal análise, em nossa perspectiva, pode nos ajudar a compreender a produção das "classes ociosas" como um processo diretamente vinculado à expulsão da população de baixa renda das áreas com maior expansão do mercado imobiliário na cidade de São Paulo. Trata-se, portanto, de uma relaçáo que reforça a necessidade de se compreender a dimensão espacial da escola pública.

Esse primeiro movimento de investigação nos apresentou importantes pontos pelos quais podemos entrar no processo de entendimento das diferentes

\section{Figura 5}

Carros de polícia em frente a E.E. Mary Moares.

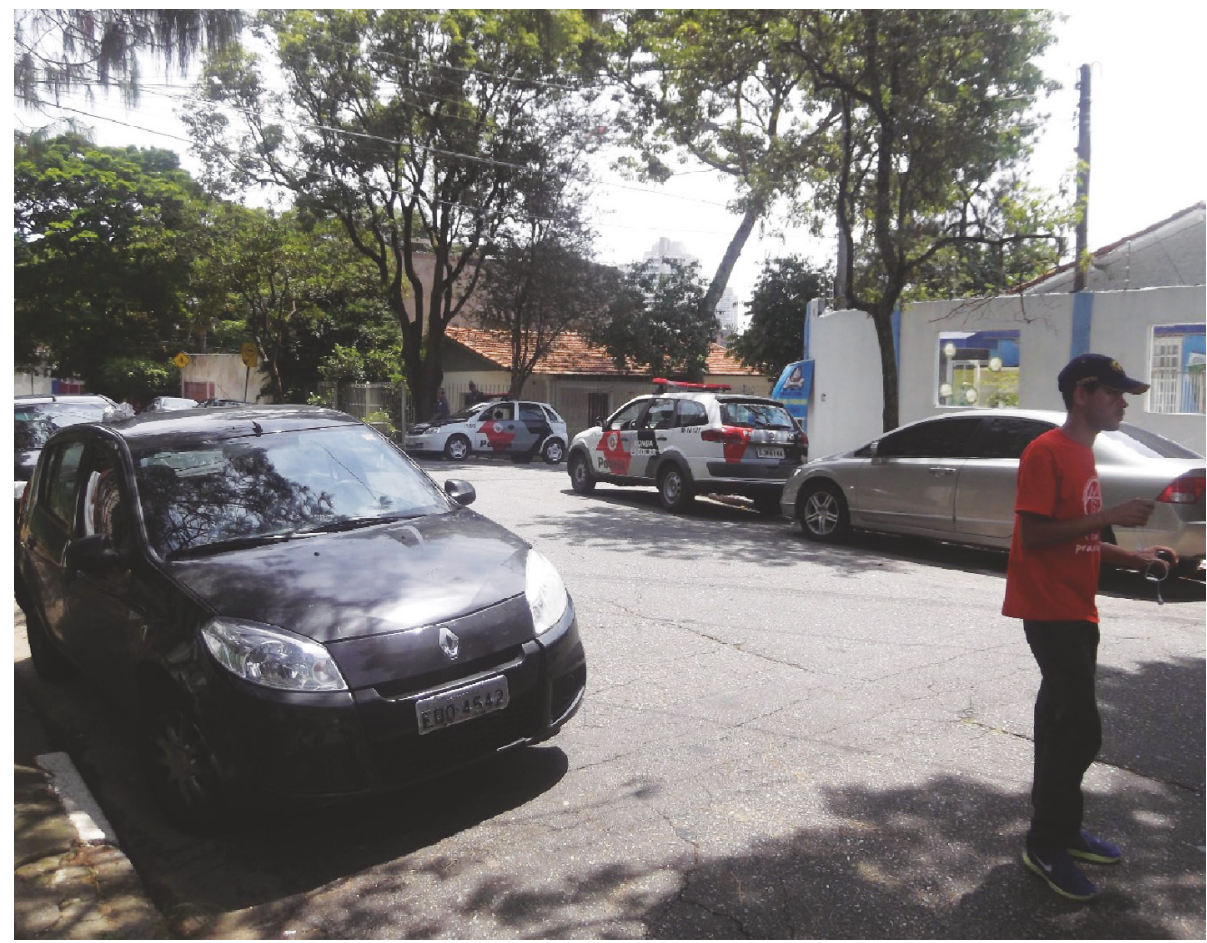

Fonte: trabalho de campo da disciplina de Estágio

Supervisionado em Ensino de Geografia, CHASSOT, T., novembro de 2015. 
intencionalidades socioespaciais do projeto de reorganização escolar da rede estadual de São Paulo. Até aqui, parece-nos evidente que há uma lógica espacial presidindo tal projeto e que busca reduzir o movimento da totalidade a certos pontos específicos da mesma, aniquilando as múltiplas relações singulares que a constituem, reafirmando a ideia da homogeneização espacial que retira a importância da condição espacial na formação dos sujeitos, múltiplos e diversos também por conta dessa condição.

Em diferentes escalas, a lógica espacial continua a sustentar as políticas postas em prática em diferentes partes do mundo, como mostraram os trabalhos de Algebaile (2009), Torres et al. (2008) e Ben Ayed (2012), apresentados na primeira parte do artigo. No caso da reorganização escolar ou do fechamento de salas de aulas, verificamos esse processo quando as escolas e os sujeitos são tomados como homogêneos, distribuídos em uma espacialidade também homogênea. As particularidades que marcam a dinâmica espacial e as práticas socioespaciais dos sujeitos não são levadas em consideração, sendo afirmada uma lógica que (na narrativa dos números e estatísticas, das médias e dados absolutos) continua a difundir uma história do mundo que silencia as vozes de diferentes sujeitos. É im-

\section{Figura 6}

Apesar de já ser uma escola com ciclo único, adaptada aos alunos e alunas, a EE Mary Moraes está na lista do fechamento.

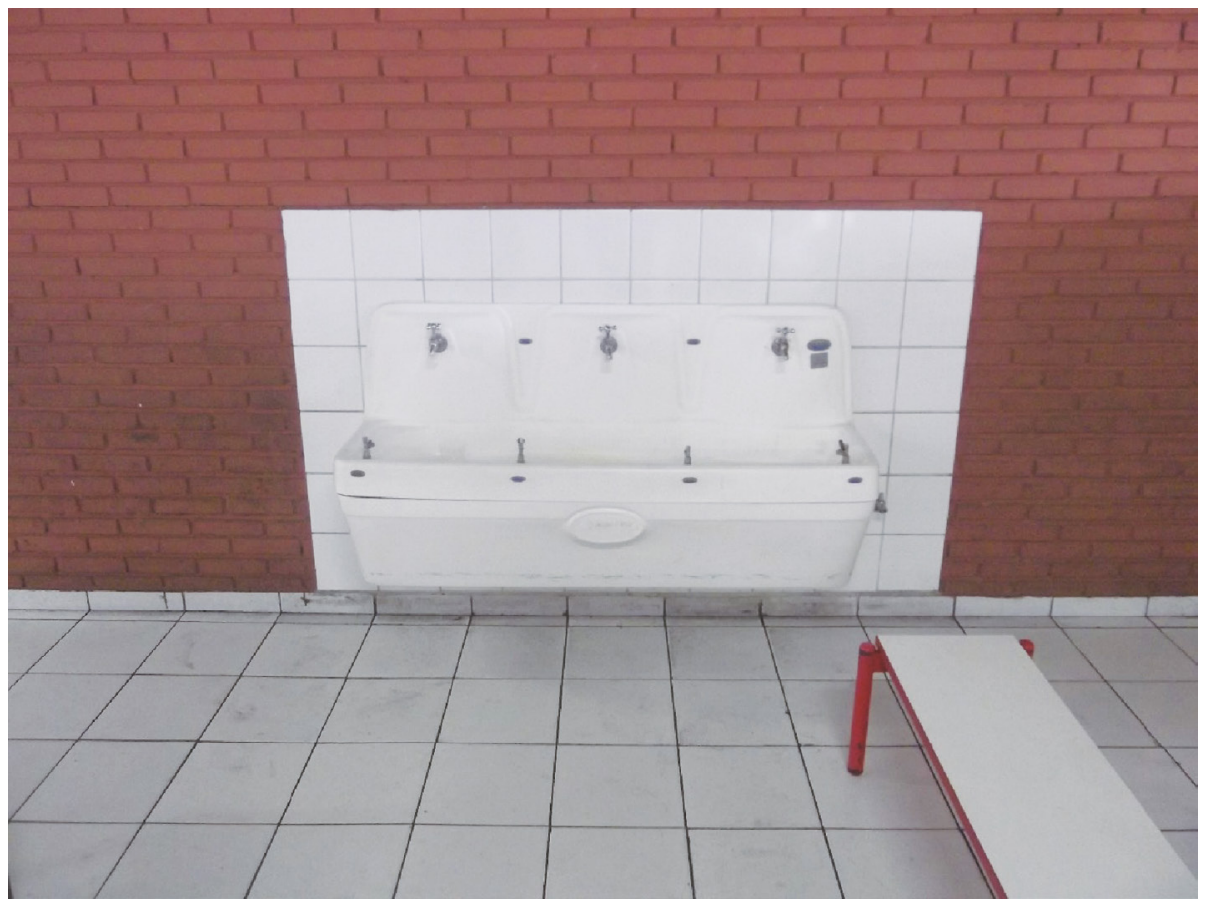

Fonte: trabalho de campo da disciplina de

Estágio Supervisionado em Ensino de Geografia, CHASSOT, T., novembro de 2015. 


\section{Figura 7}

Lançamentos imobiliários no entorno da EE Paulo Machado de Carvalho.

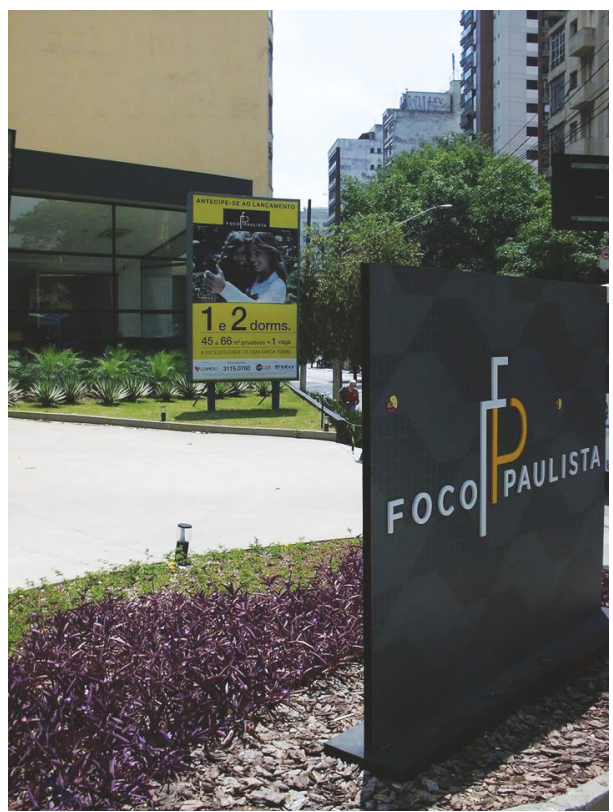

Fonte: trabalho de campo da disciplina de Estágio Supervisionado em Ensino de Geografia, GIROTTO, E.D., novembro de 2015.

\section{Figura 8}

Lançamentos imobiliários no entorno da EE Paulo Machado de Carvalho.

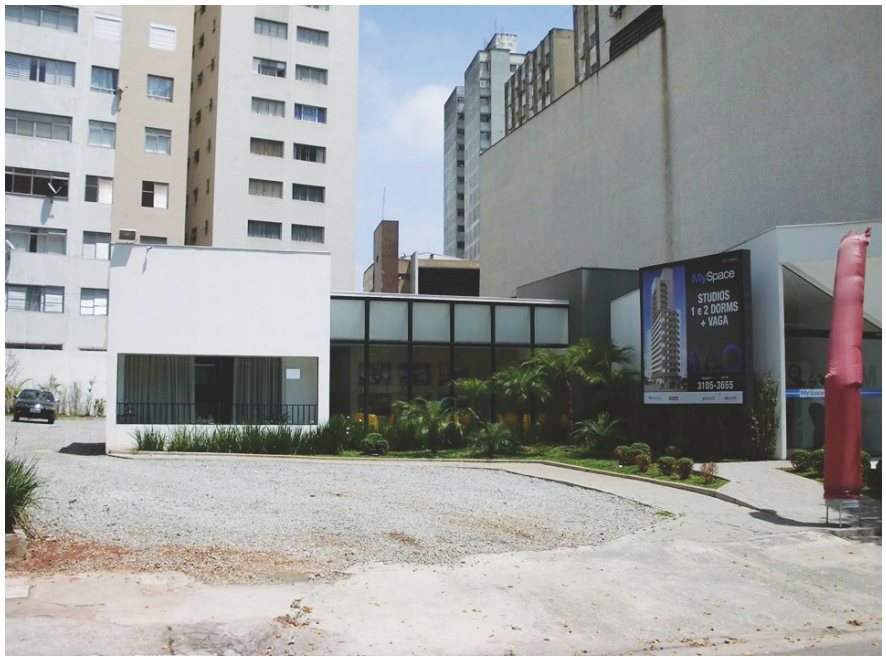

Fonte: trabalho de campo da disciplina de Estágio

Supervisionado em Ensino de Geografia, GIROTTO, E.D., novembro de 2015. 
portante destacar que esse processo se apresenta como uma cortina de fumaça a ocultar a profunda dimensão espacial das políticas realizadas que, no limite, têm contribuído para acentuar a desigualdade territorial do acesso, a permanência e a qualidade da educação pública no Brasil.

Por isso, concordamos com Massey (2008) em relação à necessidade de uma política de espacialidade que rompa com a narrativa dominante de uma lógica espacial homogênea e homogeneizante que expressa um tempo e espaço (também definidos a priori) como única trajetória possível de desenvolvimento. Nessa nova política,

Lugares, em vez de serem localizaçóes de coerências, tornam-se o foco de encontros e de não-encontros previamente não relacionados e assim essenciais para a geraçáo do novo. $\mathrm{O}$ espacial, em seu papel de trazer distintas temporalidades para novas configuraçôes, desencadeia novos processos sociais (MASSEY, 2008, p. 111).

Nesse sentido, o espaço precisa ser pensado e realizado enquanto lócus da possibilidade, da abertura, do diálogo e do conflito. Uma nova política espacial requer outra espacialidade da política, outra configuração das relaçôes sociais, uma redefinição dos homens e mulheres, não mais como abstrações, mas enquanto seres sociais nascidos a partir da ação. Pensar a escola pública nessa nova política da espacialidade passa, necessariamente, por pensar a construção do espaço público e do bem comum. Identificados os interesses predominantes hoje na escola e seus principais agentes, é preciso destituí-los como únicas trajetórias possíveis.

E aqui se destaca a importância da organização dos estudantes secundaristas e da luta que têm realizado. Em nossa perspectiva, eles têm sido os principais sujeitos da construçáo dessa nova política de espacialidade na escola pública. Com seus corpos, desejos e sonhos, destituíram a escola da narrativa unitária que buscava totalizá-la. Construindo outros discursos, práticas e ações, fizeram, no limite, outra escola, outra espacialidade. Expondo a arbitrariedade de um projeto que não os reconhece como sujeitos, os secundaristas tomaram para si as escolas e, em sua simultaneidade de coexistência, têm construído a luta por outra escola pública.

Por isso, ao ocuparem as escolas, os estudantes não apenas conseguiram barrar o fechamento das mesmas, mas lançaram o olhar de uma parcela importante da sociedade para a discussão sobre o sentido da educação pública no mundo contemporâneo, reafirmando a dimensão espacial da escola e de si mesmos. Ao se apropriarem das escolas, ocupando-as em suas diferentes dimensóes, tornaram-se também responsáveis por elas e capazes de definir a sua própria organização, produzindo outra geografia da educação pública, como aponta a Figura 9. 
Por isso, dialogando com as análises construídas por Spósito (1993) sobre a luta pela educação na cidade de São Paulo a partir de 1960, pensamos que também no movimento atual de luta dos secundaristas está presente, no limite, a luta pelo direito à cidade, que vai além do direito de frequentá-la diariamente.

\section{Figura 9}

Localização das escolas estaduais ocupadas pelos estudantes em 2015.

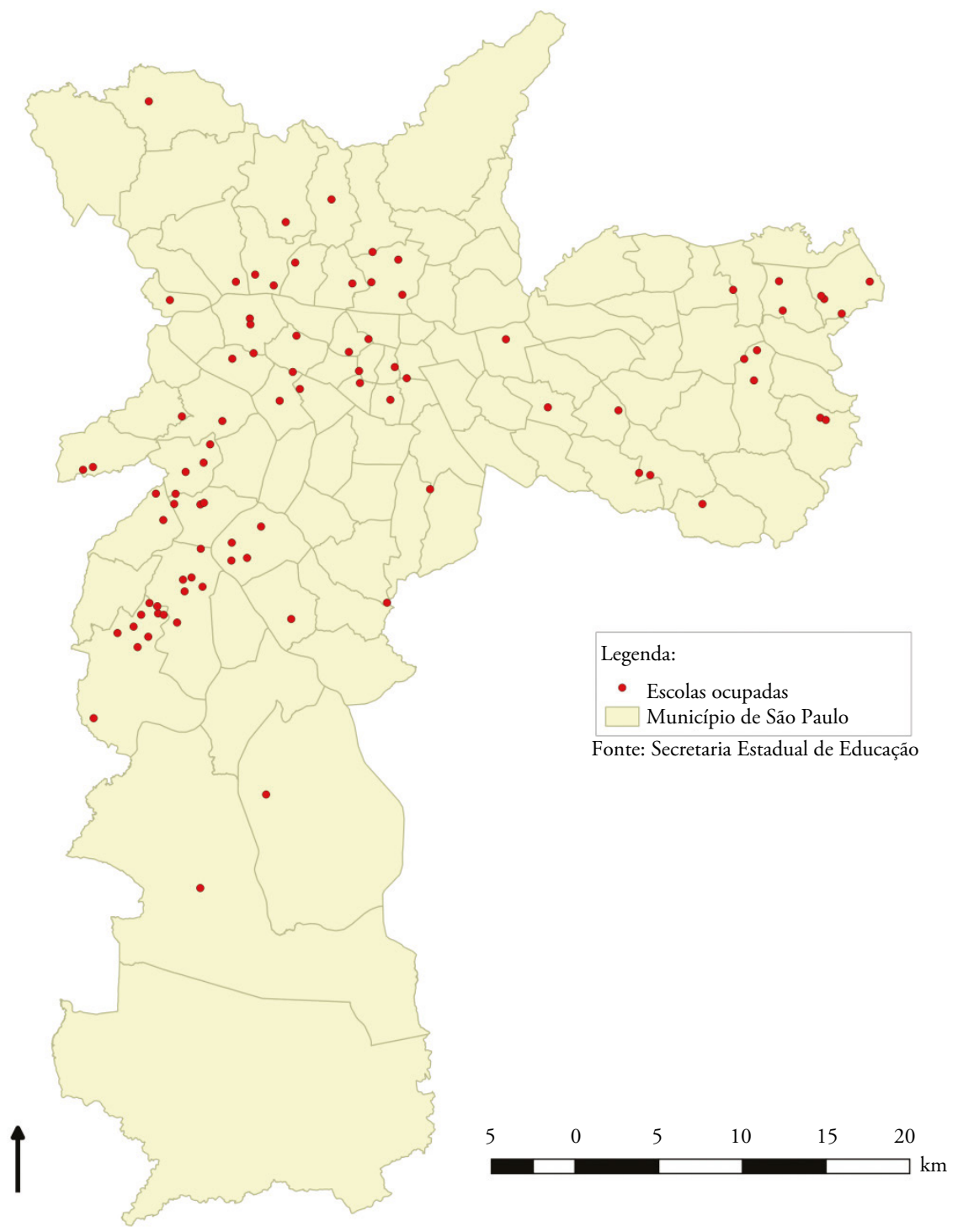

Fonte: elaborado pelo autor, a partir dos dados da Secretaria Estadual de Educação, 2016. 
O direito à cidade está, por isso, além de um direito ao acesso àquilo que já existe: é um direito de mudar a cidade mais de acordo com o nosso desejo íntimo. A liberdade para nos fazermos e nos refazermos, assim como nossas cidades, é um dos mais preciosos, ainda que dos mais negligenciados, dos nossos direitos humanos (HARVEY, 2009, p. 9).

Do momento da análise feita por Spósito até a atualidade das ocupaçôes das escolas, o que os jovens estão afirmando não é mais apenas o direito ao acesso à educação pública. Querem mais do que isso: exigem o direito de participarem da construção da escola, de pensarem suas práticas, princípios, metodologias e açóes. Por isso, nas visitas que fizemos às escolas ocupadas, nos relatos aos quais tivemos acessos (seja pelas redes sociais, seja nas conversas com outros professores e alunos), vimos uma nova escola nascer. Na reapropriaçáo do espaço-tempo, da ação que se constrói na pluralidade do encontro, alunos e alunas iniciaram a construção de um novo projeto, de uma nova política da espacialidade. Nele, os muros que separavam a vida da escola foram rompidos e aquele lugar, antes dominado quase que totalmente pela burocracia apática, pelo discurso dos números e prazos, foi preenchido pela vida dos sujeitos, suas histórias, seus sonhos, seus desejos.

\section{Considerações Finais}

Como dissemos, trata-se de pesquisa em andamento. Nossas próximas investigações buscam compreender a distribuição territorial das matrículas na rede estadual de educação, articulando essa variável com outros elementos, tais como número de lançamentos imobiliários, índice de vulnerabilidade social, taxa de crescimento vegetativo da populaçáo entre 4 e 17 anos, entre outros. Em nossa perspectiva, o cruzamento das diferentes variáveis pode contribuir para o entendimento das diferentes estratégias de apropriação espacial que estão implícitas no projeto de reorganizaçáo escolar, contribuindo no debate e na luta pela escola pública na cidade de São Paulo.

E a luta continua em curso. No momento em que o texto é finalizado, ainda são centenas de ocupaçóes realizadas por alunos e alunas em todo o país, que estão construindo uma nova espacialidade da escola pública. Nesse processo, um fato chama atenção: é preciso reinventar a educação pública, e essa reinvençấo passa pelo reconhecimento dos diferentes sujeitos que a constroem diariamente.

Ante uma política de espacialidade que os toma como homogêneos, os secundaristas afirmam as singularidades que os definem, seus lugares, de identidades e de ação. Com isso, afirmam a condição espacial da escola pública, não pelo 
discurso político acadêmico, mas pelo cuidado que se constrói no afeto cotidiano. Ao pintarem as paredes, cozinharem, organizarem saraus e rodas de conversas, partilharam conhecimentos e experiências, produziram currículos, apropriaram-se como sujeitos daquele lugar. E o mesmo passou a fazer sentido. Muitos são os relatos dos alunos e alunas que afirmaram nunca terem aprendido tanto quanto no período das ocupaçóes. E isso diz muito e deveria nos ajudar a entender a importância do reconhecimento dos diferentes sujeitos e de suas vozes na construção de uma escola pública efetivamente democrática e plural.

Para encerrar, lembramos a observação que uma aluna do Departamento de Geografia da USP fez durante uma aula: "Professor, quem ocupou as escolas foi a turma do fundão". Trata-se de uma expressáo cunhada na gíria escolar para definir aqueles alunos e alunas que pouco prestam atenção na aula, estấo desinteressados e são tachados de bagunceiros. A importância da observação da aluna está no fato de que, no processo de ocupação, a relação desses alunos e alunas com a escola se modificou profundamente. Passaram a assumir responsabilidades, a discutir sobre diferentes temas, a entender os sentidos possíveis de construir a escola e a educação pública. E, nesse processo, reinventaram suas próprias formações. A turma do fundáo representa, portanto, a crise e as possibilidades de superação da mesma; significa a importância da construção do diálogo para entender a necessidade de se elaborar, com os jovens, uma escola para a emancipação.

\section{Notas}

1. Uma análise ampla dessa primeira etapa da reorganização escolar no estado de São Paulo pode ser encontrada em Adriáo (2008).

2. No site http://gentrificacao.reporterbrasil.org.br/ é possível encontrar a consolidação das pesquisas sobre essa temática.

\section{Referências}

ADRIÃO, T. Oferta do ensino fundamental em São Paulo: um novo modelo. Educação e Sociedade, Campinas, v. 29, n. 102, jan./abr. 2008.

ALGEBAILE, E. Escola pública e pobreza no Brasil: a ampliação para menos. Rio de Janeiro: Lamparina, 2009.

BEN AYED, C. As desigualdades socioespaciais de acesso aos saberes: uma perspectiva de renovação da sociologia das desigualdades escolares? Educação e Sociedade, Campinas, v. 33, n.120, jul./set. 2012.

FRANÇA, G.C. Urbanização e educação: da escola de bairro à escola de passagem. 2010. Tese (Doutorado em Geografia Humana). Faculdade de Filosofia, Letras e Ciências Humanas, Universidade de São Paulo, São Paulo. 
GIROTTO, E.D. Escola, lugar e poder: as aventuras de um professor-pesquisador entre o subúrbio e a periferia. 2009. Dissertação (Mestrado). Faculdade de Filosofia, Letras e Ciências Humanas, Universidade de São Paulo, São Paulo.

HARVEY, D. "A liberdade da cidade”. GEOUSP Espaço e Tempo, São Paulo, n. 26, 2009.

KOWARICK, L. A espoliação urbana. São Paulo: Paz e Terra, 1979.

LEFEBVRE, H. O direito à cidade. São Paulo: Documentos, 1969.

MASSEY, D. Pelo espaço: uma nova política da espacialidade. Rio de Janeiro: Bertrand Brasil, 2008.

PEREIRA, L. A escola numa área metropolitana. São Paulo: Edusp, 1967.

SPÓSITO, M.P. A ilusão fecunda. São Paulo: Hucitec, 1993.

. O povo vai à escola. São Paulo: Loyola, 1984.

TORRES, H.G.; BICHIR, R. M.; GOMES, S.; CARPIN, T. R P. A educação na periferia de São Paulo: ou como pensar as desigualdades educacionais? In: RIBEIRO, L.C.Q.; KAZTMAN, R. A cidade contra a escola? - segregação urbana e desigualdades educacionais em grandes cidades da América Latina. Rio de Janeiro: Letra Capital, 2008.

Recebido em 7 de agosto de 2016.

Aprovado em 19 de outubro de 2016. 